\title{
Baseline Sensitivity of Cercospora zeae-maydis to Quinone Outside Inhibitor Fungicides
}

\author{
C. A. Bradley and D. K. Pedersen, Department of Crop Sciences, University of Illinois, Urbana 61801
}

\begin{abstract}
Bradley, C. A., and Pedersen, D. K. 2011. Baseline sensitivity of Cercospora zeae-maydis to quinone outside inhibitor fungicides. Plant Dis. 95:189-194.

Cercospora zeae-maydis, the causal agent of gray leaf spot on corn (Zea mays), can cause severe yield loss in the United States. Quinone outside inhibitor $(\mathrm{QoI})$ fungicides are effective tools that can be used to manage gray leaf spot, and their use has increased in corn production in the United States. In total, 61 C. zeae-maydis isolates collected from fields in which QoI fungicides had never been applied were tested in vitro using azoxystrobin-, pyraclostrobin-, or trifloxystrobin-amended medium to determine the effective fungicide concentration at which $50 \%$ of the conidial germination was inhibited $\left(\mathrm{EC}_{50}\right)$. The effect of salicylhydroxamic acid (SHAM) also was evaluated for seven isolates to determine whether C. zeae-maydis is capable of using alternative respiration in azoxystrobin-amended medium. All seven $C$. zeae-maydis isolates tested had significantly greater $(P<0.02) \mathrm{EC}_{50}$ values

when SHAM was not included in medium amended with azoxystrobin, indicating that $C$. zeae-maydis has the potential to utilize alternative respiration to overcome QoI fungicide inhibition in vitro. Baseline $\mathrm{EC}_{50}$ values of azoxystrobin ranged from 0.003 to $0.031 \mu \mathrm{g} / \mathrm{ml}$, with mean and median values of 0.018 and $0.019 \mu \mathrm{g} / \mathrm{ml}$, respectively. Baseline $\mathrm{EC}_{50}$ values of pyraclostrobin ranged from 0.0003 to $0.0025 \mu \mathrm{g} / \mathrm{ml}$, with mean and median values of 0.0010 and $0.0010 \mu \mathrm{g} / \mathrm{ml}$, respectively. Baseline $\mathrm{EC}_{50}$ values of trifloxystrobin ranged from 0.0004 to $0.0034 \mu \mathrm{g} / \mathrm{ml}$, with mean and median values of 0.0023 and 0.0024 $\mu \mathrm{g} / \mathrm{ml}$, respectively. These baseline sensitivity values will be used in a fungicide resistance monitoring program to determine whether shifts in sensitivity to QoI fungicides are occurring in C. zeae-maydis populations.
\end{abstract}

Gray leaf spot, caused by Cercospora zeae-maydis, is a major disease of corn (Zea mays) in the U.S. Corn Belt. Yield reductions have been reported to be as high as nearly $70 \%$ in the United States when gray leaf spot was severe on susceptible hybrids (32). Growers can manage gray leaf spot by planting less-susceptible hybrids, burying crop residues with tillage, rotating with nonhost crops, and applying foliar fungicides (8).

The use of foliar fungicides on hybrid corn in the United States has become more popular since quinone outside inhibitor (QoI) fungicides were registered for use on corn in the early to mid2000s. To date, QoI fungicide active ingredients registered for use on corn in the United States include azoxystrobin (Syngenta Crop Protection, Greensboro, NC), pyraclostrobin (BASF Corporation, Research Triangle Park, NC), and trifloxystrobin (Bayer CropScience, Research Triangle Park, NC). Azoxystrobin and pyraclostrobin are marketed as solo-active-ingredient products (Quadris and Headline, respectively) on corn, and azoxystrobin, pyraclostrobin, and trifloxystrobin are marketed as products premixed with demethylation inhibitor (DMI) fungicides. As QoI-DMI premix fungicide products, azoxystrobin and trifloxystrobin are mixed with propiconazole (Quilt or Quilt Xcel and Stratego, respectively), and pyraclostrobin is mixed with metconazole (Headline AMP). Beginning in 2007, use of QoI foliar fungicide products on corn increased dramatically. Estimates of approximately 4.3 to 5.6 million ha out of an approximate total of 30.8 million ha of corn in the Midwestern United States were sprayed with a foliar fungicide in 2007 (22). Prior to 2007, foliar fungicide application to hybrid corn in the Midwest was rare. The factors that contributed to the increased use of foliar fungicides on corn grown in the Midwestern United States involved both disease-related and nondisease-related factors, and have been described by Bradley and Ames (5). When

Corresponding author: C. A. Bradley, E-mail: carlbrad@illinois.edu

Accepted for publication 5 October 2010.

doi:10.1094/PDIS-05-10-0356

(C) 2011 The American Phytopathological Society
QoI fungicide applications to corn are directed toward foliar disease control, gray leaf spot is one of the major diseases targeted. Complete resistance to gray leaf spot does not exist in any corn hybrids (32), and foliar fungicides may be used in a profitable manner to control gray leaf spot on hybrids with low resistance levels (23).

The Fungicide Resistance Action Committee (FRAC; Crop Life International, Brussels) has determined that QoI fungicides pose a high risk of resistance development, and over 30 fungal pathogen species across 20 genera have been reported to show field resistance toward QoI fungicides (11). With the increased use of QoI fungicides on corn in the United States and the associated risk of resistance to QoI fungicides, it is important that C. zeae-maydis baseline sensitivities to QoI fungicides be established to facilitate a monitoring program that will be able to detect shifts in sensitivity.

QoI fungicides block electron transport at the quinol-oxidizing site of the cytochrome $b_{1}$ complex (complex III) in the mitochondrial respiration chain; thus, they inhibit respiration of affected fungi $(1,38)$. Some fungi possess an alternative respiration pathway which allows them to bypass complex III and IV in the mitochondrial respiration chain, which is accounted for by the presence of the respiratory enzyme alternative oxidase $(18,20)$. The alternative respiration pathway has allowed fungal spores to germinate in the presence of high doses of QoI fungicides $(25,31,39)$; however, this alternative respiration has been observed only in vitro $(25,26,31,39)$. The alternative respiration pathway is not thought to occur in nature when fungi are exposed to QoI fungicides, because plant-produced flavones may prevent the induction of alternative oxidase $(21,25,26)$. The ability of $C$. zeae-maydis to utilize alternative respiration has not been reported.

The objectives of this research were to (i) determine whether $C$. zeae-maydis isolates can utilize alternative respiration during in vitro QoI fungicide sensitivity assays and (ii) establish baseline sensitivities of $C$. zeae-maydis isolates to azoxystrobin, pyraclostrobin, and trifloxystrobin.

\section{Materials and Methods}

C. zeae-maydis isolates. In total, 64 C. zeae-maydis isolates were obtained (Table 1). These isolates were collected from corn 
fields in 12 different states (Colorado, Illinois, Indiana, Iowa, Kansas, Missouri, Nebraska, North Carolina, Ohio, Oklahoma, Pennsylvania, and West Virginia). Twenty-nine isolates were obtained from historical isolate collections, and were all collected prior to 2001. Thirty-five isolates were collected during the 2007 growing season. In all cases, isolates were obtained from commercial fields and field research plots in which QoI fungicides had never been applied. Isolates were kept for long-term storage in cryogenic tubes with $15 \%$ glycerol solution at $-80^{\circ} \mathrm{C}$.

For all experiments, isolates were prepared using methods adapted from Pasche et al. (27) and Wise et al. (33). Thawed fungal plugs were placed onto petri dishes (100 $\mathrm{mm}$ in diameter) containing V8 juice agar (3) amended with rifampicin ( $25 \mathrm{mg} / \mathrm{liter})$ and were incubated at room temperature in the dark for 3 to 5 days until isolates were producing conidia. These isolates were transferred to new V8 juice agar and incubated several times to produce enough conidia to conduct the assays. Sterile distilled water was added to the $C$. zeae-maydis cultures and bent glass rods were used to dislodge conidia to make a conidial suspension. The conidial suspension was filtered through a double layer of sterile cheesecloth to remove mycelial debris. The conidial suspension was adjusted to approximately $1 \times 10^{5}$ conidia/ml, and $75 \mu \mathrm{l}$ was spread onto potato dextrose agar (PDA; Becton, Dickinson, and Company, Franklin Lakes, NJ) (amended with fungicide dilutions in some cases) in each of two replicate petri dishes $(60 \mathrm{~mm}$ in diameter) with a bent glass rod for conidial germination assays. The petri dishes were held at $21^{\circ} \mathrm{C}$ for $18 \mathrm{~h}$ in the dark. Following incubation, 50 conidia per plate were visually assessed microscopically $(\times 100)$ and evaluated for germination. A conidium was considered to be germinated if the germ tube was at least as long as the length of the conidium.

Determination of alternative respiration in C. zeae-maydis. The objective of this experiment was to determine whether alternative respiration is induced in $C$. zeae-maydis when exposed to a QoI fungicide (azoxystrobin). Seven isolates of $C$. zeae-maydis (BF072, BF074, BF07133, BF07149, BF07175, BF07183, and BF07558) were selected using the random function of Microsoft Office Excel 2007 (Microsoft Corp., Redmond, WA) and tested. A stock solution of technical-grade azoxystrobin ( $96 \%$ a.i.; Syngenta Crop Protection) was prepared at a concentration of $100 \mathrm{mg} / \mathrm{ml}$ in acetone. Serial dilutions of the azoxystrobin stock solutions were prepared in acetone and amended to PDA at 0, 0.001, 0.01, 0.1, 1, and $10 \mu \mathrm{g} / \mathrm{ml}$. In addition, salicylhydroxamic acid (SHAM; SigmaAldrich, St. Louis) at $60 \mu \mathrm{g} / \mathrm{ml}$ dissolved in methanol was either added or not added to the PDA. All amendments were added to the autoclaved PDA after it had cooled to $55^{\circ} \mathrm{C}$. SHAM is used in QoI fungicide in vitro assays to prevent fungi from using an alternative respiration pathway (25). A preliminary study that evaluated different concentrations of SHAM in PDA on conidial germination determined that SHAM at $60 \mu \mathrm{g} / \mathrm{ml}$ was the highest rate tested that did not significantly $(P \leq 0.05)$ reduce $C$. zeae-maydis conidial germination (unpublished data). Conidia of $C$. zeae-maydis were incubated and conidial germination was measured as described previously. For each of the replicate plates, conidial germination was converted to percent inhibition compared with the azoxystrobin at $0 \mu \mathrm{g} / \mathrm{ml}$ control plates by 100 - ([percent germination of azoxystrobin-amended $] /[$ mean percent germination of $0 \mu \mathrm{g} / \mathrm{ml}])$. The azoxystrobin fungicide concentration that effectively inhibited conidial germination by $50 \%$ of the azoxystrobin control at $0 \mu \mathrm{g} / \mathrm{ml}$ $\left(\mathrm{EC}_{50}\right)$ was determined for each $C$. zeae-maydis isolate by linear interpolation using the two concentrations that bracketed 50\% (30).

This experiment was arranged as a completely randomized design (CRD) with two replicate plates per isolate, and the experiment was repeated once. Data from each experiment were analyzed first separately using the general linear model procedure (PROC GLM) in SAS (version 9.2; SAS Institute, Inc., Cary, NC) to compute variances; then, a two-tailed $F$ test for equality of variances was conducted to determine whether data from trials could be combined. Combined data were analyzed using PROC GLM in SAS, and least-square means $t$ tests (PDIFF option in SAS) were used to compare $\mathrm{EC}_{50}$ values of individual $C$. zeae-maydis isolates on SHAM-amended PDA versus nonamended PDA.

Establishment of baseline $\mathbf{E C}_{\mathbf{5 0}}$ values. Technical-grade formulations of azoxystrobin (96\% a.i.; Syngenta Crop Protection), pyraclostrobin (98\% a.i.; BASF Corporation), and trifloxystrobin (98\% a.i.; Bayer CropScience) each were used to prepare stock solutions at concentrations of $100 \mathrm{mg} / \mathrm{ml}$ in acetone. Serial dilutions in acetone were prepared for each fungicide. C. zeae-maydis fungicide sensitivity was evaluated by determining conidial germination on PDA amended with different concentrations of each fungicide. When PDA had been cooled to $55^{\circ} \mathrm{C}$, azoxystrobin was amended to PDA at $0.0001,0.001,0.01,0.1$, and $1 \mu \mathrm{g} / \mathrm{ml}$, and pyraclostrobin and trifloxystrobin each were amended to PDA at $0.0001,0.001,0.01$, and $0.1 \mu \mathrm{g} / \mathrm{ml}$. Azoxystrobin, pyraclostrobin, and trifloxystrobin $\mathrm{EC}_{50}$ values for 61 of the C. zeae-maydis baseline isolates listed in Table 1 (all isolates listed except BF07149, $\mathrm{BF} 07183$, and BF07558) were determined using the methods described in the previous sections.

Because of time and space constraints, the baseline isolates were assayed for their sensitivities to the fungicides over multiple trials. An assay reproducibility test described by Wong and Wilcox (34) was used to validate each trial. For this reproducibility test, an internal control isolate (BF072) was assayed for its sensitivity to azoxystrobin, pyraclostrobin, and trifloxystrobin, and $\mathrm{EC}_{50}$ values were determined using the methods described previously in 10 separate trials. The mean, standard error, and 95\% confidence limits were calculated for this isolate as described by Wong and Wilcox (34). If the $\mathrm{EC}_{50}$ value of the internal control isolate did not

Table 1. Collection information for baseline isolates of Cercospora zeae-maydis from corn

\begin{tabular}{ll}
\hline Year, state & \multicolumn{1}{c}{ Isolates } \\
\hline Prior to 2001 & \\
Illinois & BF072, BF073, BF07129, BF07132, BF07133, BF07134 \\
Indiana & BF078, BF079, BF0712, BF0713 \\
Nebraska & BF074 \\
North Carolina & BF076, BF07119, BF07120, BF07121, BF07122, BF07123, BF07124, BF07125, BF07126 \\
Ohio & BF077, BF0710, BF0715, BF07149, BF07150, BF07151 \\
Oklahoma & BF075 \\
Pennsylvania & BF0711 \\
West Virginia & BF071 \\
2007 & \\
Colorado & BF07416 \\
Illinois & BF07173, BF07175, BF07177, BF07183, BF07222, BF07223, BF07227, BF07249, BF07267, BF07299, \\
Indiana & BF07371, BF07436, BF07440, BF07548, BF07568 \\
Iowa & BF07243 \\
Kansas & BF07380 \\
Missouri & BF07403, BF07408, BF07409, BF07414 \\
Nebraska & BF07397, BF07399, BF07481, BF07511, BF07514, BF07522, BF07525, BF07528, BF07558 \\
\hline
\end{tabular}


fall within the $95 \%$ confidence limits in the subsequent trials designed to establish baseline sensitivities of all the isolates, then those trials were repeated until the $\mathrm{EC}_{50}$ of the internal control isolate was within its $95 \%$ confidence limit. For each trial, isolates were assayed on two replicate plates. Each isolate was assayed in at least two separate trials.

For each fungicide $\mathrm{EC}_{50}$ value distribution, the mean and median were calculated, and the distribution was tested for normality using the univariate procedure with the normal option (PROC UNIVARIATE NORMAL) in SAS (version 9.2). The Shapiro-Wilk test was used to determine normality. Associations among azoxystrobin, pyraclostrobin, and trifloxystrobin $\mathrm{EC}_{50}$ values were evaluated using Pearson correlation analysis (PROC CORR) in SAS (version 9.2).

\section{Results}

Determination of alternative respiration in C. zeae-maydis. Separate analysis of experiments conducted to determine the im-

Table 2. Comparison of azoxystrobin effective concentration at which $50 \%$ of conidial germination was inhibited values $(\mu \mathrm{g} / \mathrm{ml})$ of seven Cercospora zeae-maydis baseline isolates in nonamended potato dextrose agar and salicylhydroxamic acid (SHAM)-amended potato dextrose agar

\begin{tabular}{lccc}
\hline Isolate & Nonamended & SHAM-amended & $\boldsymbol{P}_{\text {value }}$ \\
\hline BF072 & 0.0620 & 0.0256 & 0.0001 \\
BF074 & 0.0800 & 0.0251 & 0.0001 \\
BF07133 & 0.0345 & 0.0151 & 0.0055 \\
BF07149 & 0.0358 & 0.0051 & 0.0001 \\
BF07175 & 0.0350 & 0.0049 & 0.0001 \\
BF07183 & 0.0371 & 0.0209 & 0.0188 \\
BF07558 & 0.0401 & 0.0100 & 0.0001 \\
Mean & 0.0451 & 0.0152 & 0.0001 \\
\hline
\end{tabular}

a $P$ value for individual isolates were determined using least-square means $t$ tests; $P$ value for comparison of overall isolate means of nonamended and SHAM-amended was determined from an $F$ test. pact of SHAM on conidial germination in the presence and absence of azoxystrobin produced variances that were not significantly different according to an $F$ test $(P=0.2880)$; therefore, experiments were combined for analysis. The analysis of variance of $\mathrm{EC}_{50}$ values of the seven isolates exposed to azoxystrobin with and without SHAM indicated that the main effects of isolate and SHAM were significant $(P=0.0001)$ and the interaction of isolate-SHAM was significant $(P=0.0087)$. In all seven isolates tested, $\mathrm{EC}_{50}$ values were significantly $(P<0.02)$ greater when SHAM was not included in the azoxystrobin-amended medium (Table 2).

Establishment of baseline $\mathbf{E C}_{\mathbf{5 0}}$ values. The range of $\mathrm{EC}_{50}$ values for isolates exposed to azoxystrobin was 0.003 to $0.031 \mu \mathrm{g} / \mathrm{ml}$ and the mean and median values were 0.018 and $0.019 \mu \mathrm{g} / \mathrm{ml}$, respectively (Fig. 1). The azoxystrobin $\mathrm{EC}_{50}$ values were normally distributed $(P=0.0682)$. For pyraclostrobin, the range of $\mathrm{EC}_{50}$ values was 0.0003 to 0.0025 and the mean and median values were 0.0010 and $0.0010 \mu \mathrm{g} / \mathrm{ml}$, respectively (Fig. 2). The pyraclostrobin $\mathrm{EC}_{50}$ values were not normally distributed $(P=0.0001)$. For trifloxystrobin, the range of $\mathrm{EC}_{50}$ values was 0.0004 to $0.0034 \mu \mathrm{g} / \mathrm{ml}$ and the mean and median values were 0.0023 and $0.0024 \mu \mathrm{g} / \mathrm{ml}$, respectively (Fig. 3). The trifloxystrobin $\mathrm{EC}_{50}$ values were not normally distributed $(P=0.0008)$. Pearson correlation analysis indicated that there were significant positive baseline sensitivity relationships between azoxystrobin and pyraclostrobin sensitivities $(P=0.0061 ; r=0.34)$, between azoxystrobin and trifloxystrobin $(P$ $=0.0464 ; r=0.25)$, and between pyraclostrobin and trifloxystrobin $(P=0.0001 ; r=0.53)$.

\section{Discussion}

In our in vitro trials, sensitivities of $C$. zeae-maydis isolates were increased when SHAM was added to azoxystrobin-amended medium. This suggests that $C$. zeae-maydis may use the alternative respiration pathway to overcome conidial germination inhibition caused by QoI fungicides. Other fungal plant pathogens also have

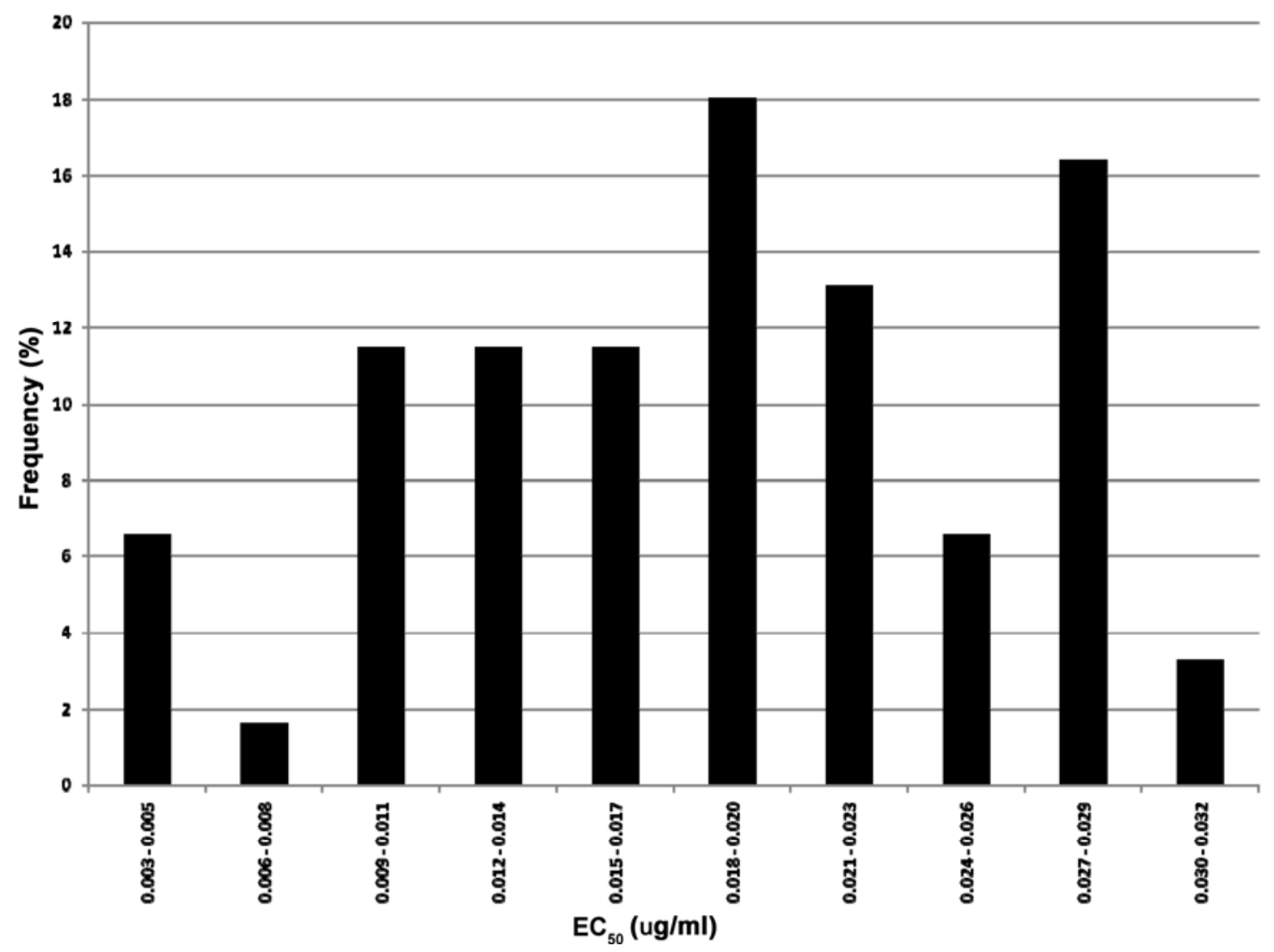

Fig. 1. Sensitivity distribution of effective concentration at which $50 \%$ of conidial germination was inhibited $\left(\mathrm{EC}_{50}\right.$ values) for 61 baseline isolates of Cercospora zeae-maydis to azoxystrobin. 


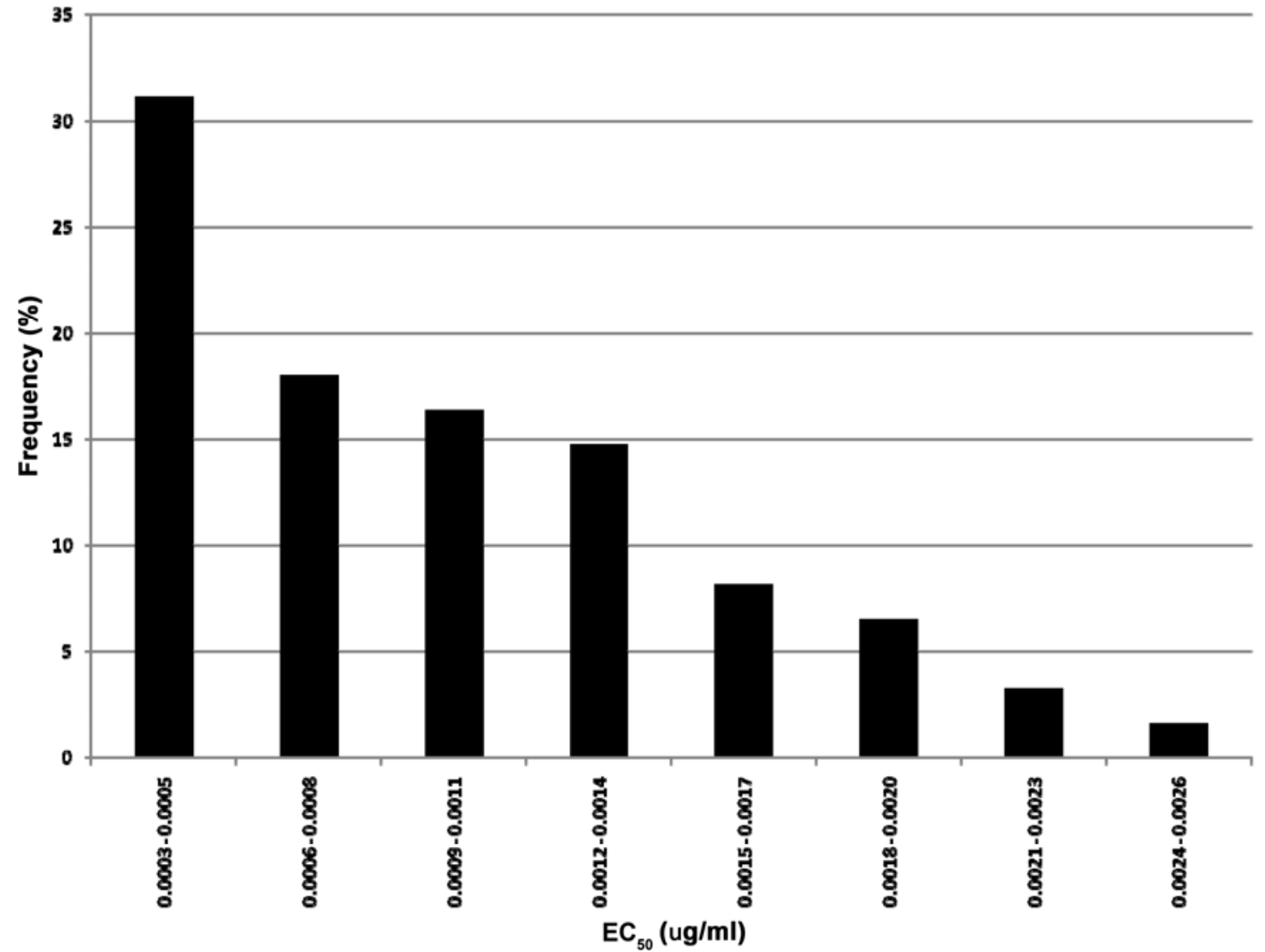

Fig. 2. Sensitivity distribution of effective concentration at which $50 \%$ of conidial germination was inhibited ( $\mathrm{EC}_{50}$ values) for 61 baseline isolates of Cercospora zeae-maydis to pyraclostrobin.

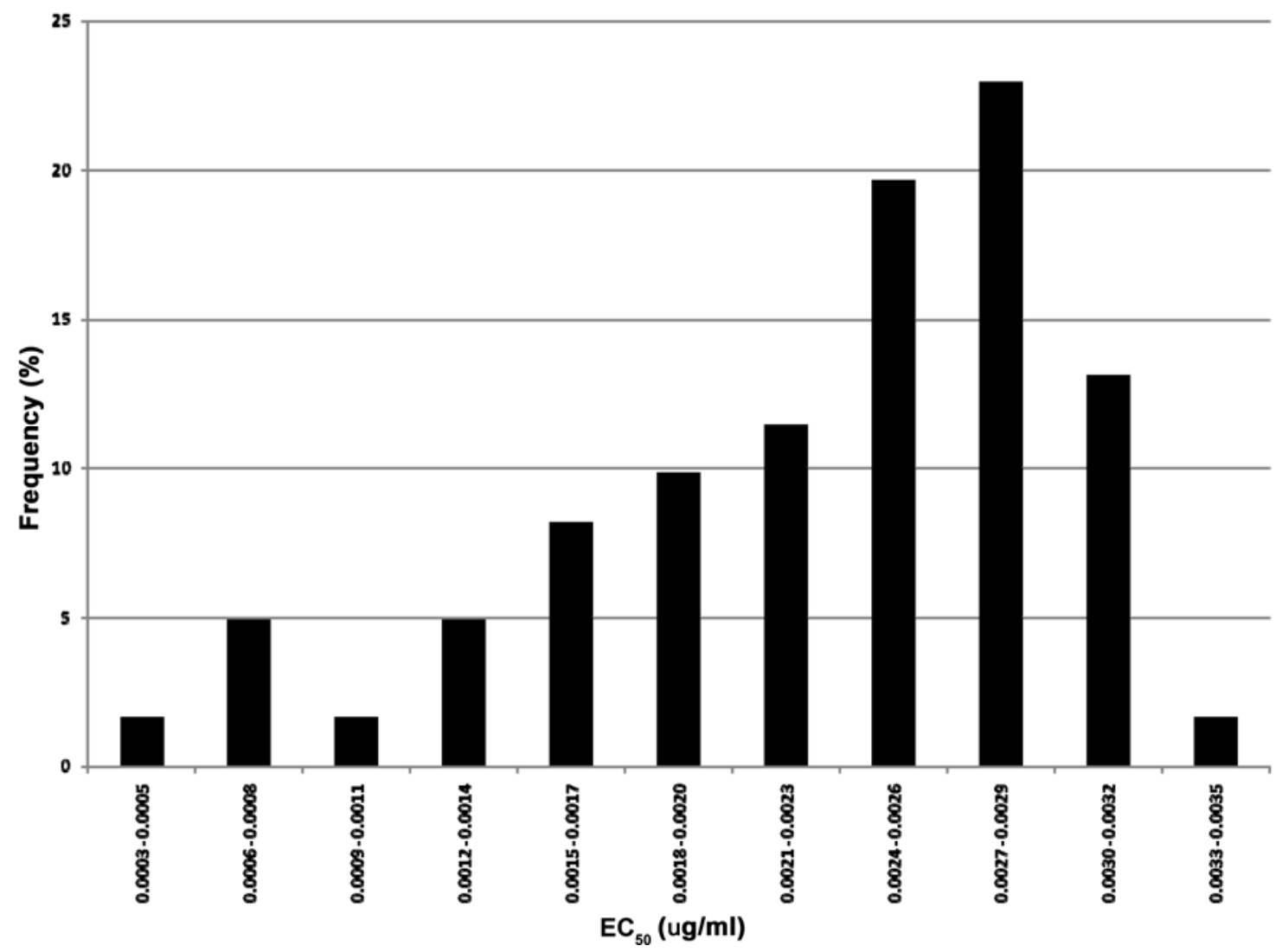

Fig. 3. Sensitivity distribution of effective concentration at which $50 \%$ of conidial germination was inhibited $\left(\mathrm{EC}_{50}\right.$ values) for 61 baseline isolates of Cercospora zeae-maydis to trifloxystrobin. 
been reported to utilize the alternative respiration pathway to overcome inhibitory effects of QoI fungicides $(25,31,33,39)$, including the related pathogen $C$. beticola (19). Because this alternative respiration pathway present in some fungi has been observed only in vitro $(25,26,31,39)$, it is unlikely that it will affect the sensitivity of C. zeae-maydis populations to fungicides in vivo. It is important to note that the alternative respiration pathway was present in isolates never exposed to QoI fungicides in our study as well as other studies with different fungi $(33,39)$; therefore, it is important to include SHAM in QoI fungicide in vitro assays conducted with $C$. zeae-maydis.

The ranges in sensitivities of C. zeae-maydis baseline isolates for azoxystrobin, pyraclostrobin, and trifloxystrobin were relatively narrow (approximately 10-fold or less). This is similar to other baseline sensitivity ranges of other fungi. Sensitivity ranges of fungi to azoxystrobin have been reported to be anywhere from approximately 2 - to 11 -fold $(9,27,31,33,35)$. Sensitivity ranges of fungi to pyraclostrobin have been reported to range from approximately 3 - to 15 -fold $(23,24,30,33,35)$. The sensitivity range of Pyricularia grisea baseline isolates to trifloxystrobin was 6-fold (31) whereas the sensitivity range of Mycosphaerella fijiensis baseline isolates to trifloxystrobin ranged from 2-fold to 29-fold (10).

The shape of the baseline for azoxystrobin was normally distributed but the baselines for pyraclostrobin and trifloxystrobin were not normally distributed. According to Russell (29), the shape of the baseline distribution gives no information on the absolute risk of resistance developing; however, if the baseline shows a skew distribution with a long tail for the less sensitive end, then this may be a warning that resistance is possible. The baseline for pyraclostrobin is skewed toward the less sensitive end, which may indicate a warning that resistance in $C$. zeae-maydis populations is possible. On the other hand, the relatively narrow range in sensitivity of $C$. zeae-maydis baseline isolates to all three QoI fungicides tested may indicate less potential for resistance (17). In general, the use of baseline sensitivities to assess risk of resistance is limited $(7,17,29)$; thus, monitoring QoI fungicide sensitivity of $C$. zeaemaydis populations over time will be needed to determine sensitivity shifts.

Conidial germination of C. zeae-maydis isolates was most inhibited by pyraclostrobin and trifloxystrobin compared with azoxystrobin in our in vitro assays. Isolates were approximately $\geq 10$ times more sensitive to pyraclostrobin or trifloxystrobin when comparing mean $\mathrm{EC}_{50}$ values. This is similar to what has been reported by Pasche et al. (27), where Alternaria solani isolates were approximately 10 times more sensitive to pyraclostrobin or trifloxystrobin than they were to azoxystrobin. Wong and Wilcox (35) reported that Uncinula necator was approximately 3 times more sensitive to pyraclostrobin than azoxystrobin or trifloxystrobin, and Wise et al. (33) reported that Ascochyta rabiei was approximately 10 times more sensitive to pyraclostrobin than azoxystrobin, which shows that the intrinsic activities of QoI fungicides can differ and that the intrinsic activity of pyraclostrobin is often greater than azoxystrobin. Intrinsic activity may not provide a good indication of relative fungicide efficacy, however. When compared in field studies, no differences were observed between azoxystrobin and pyraclostrobin for gray leaf spot control $(4,5)$.

Plant-pathogenic fungi that are able to generate variation through sexual recombination may have an increased risk of developing resistance to fungicides $(7,16)$. Currently, C. zeae-maydis is known to only have an anamorphic stage; however, Groenewald et al. (13) proposed that a sexual cycle may be active in C. zeae-maydis based on the presence of both mating types in approximately even proportions. Decreases in QoI fungicide sensitivities have been reported in fungi without known teleomorphic stages, such as Alternaria solani and $C$. beticola $(27,30)$; thus, it is not necessary that a fungus contain a teleomorphic stage for a shift in QoI sensitivity to occur.

An increase in use of QoI fungicides in corn will increase the selection pressure toward a shift in reduced sensitivity. An important anti-resistance management practice is to use a fungicide only when necessary $(6,16)$. QoI fungicides are beginning to be marketed and promoted for their potential nondisease control properties. Examples of potential nondisease control properties of QoI fungicides that have been observed in greenhouse and laboratory studies include delayed senescence, altered amounts of plant hormones, increased activity of antioxidative enzymes, and increased activity of nitrate reductase $(12,14,15,28,36-38)$. Recently, the United States Environmental Protection Agency granted a supplemental label registration for use of Headline fungicide (pyraclostrobin) on registered crops for disease control and plant health (2). For corn, this label states that the fungicide can provide benefits such as improved stalk strength and better harvestability, better tolerance to hail, and more uniform seed size. An increase in the number of QoI applications to corn for reasons other than disease control may increase the risk of QoI sensitivity shifts in corn pathogens such as $C$. zeae-maydis, thus increasing the importance of establishing QoI fungicide baseline sensitivities and implementing a fungicide resistance monitoring program for C. zeae-maydis.

\section{Acknowledgments}

We thank P. Balint-Kurti (United States Department of Agriculture-Agricultural Research Service [USDA-ARS], North Carolina State University), L. Dunkle (USDA-ARS, Purdue University), T. Jackson (University of Nebraska), D. Jardine (Kansas State University), P. Paul (Ohio State University), A. Robertson (Iowa State University), L. Sweets (University of Missouri), and D. White (University of Illinois) for contributing C. zeae-maydis isolates; J. Hardimon and G. Zhang for their assistance in the laboratory; and BASF Corporation, Bayer CropScience, and Syngenta Crop Protection for providing technical-grade fungicides. This project was supported by the USDA National Institute of Food and Agriculture, Hatch project number ILLU-802-378.

\section{Literature Cited}

1. Bartlett, D. W., Clough, J. M., Godwin, J. R., Hall, A. A., Hamer, M., and Parr-Dobrzanski, B. 2002. The strobilurin fungicides. Pest Manage. Sci. 58:649-662.

2. BASF Corporation. 2008. Headline Fungicide Supplemental Label NVA 2008-04-088-0327. BASF Corp., Research Triangle Park, NC.

3. Beckman, P. M., and Payne, G. A. 1983. Cultural techniques and conditions influencing growth and sporulation of Cercospora zeae-maydis and lesion development in corn. Phytopathology 73:286-289.

4. Bradley, C. A., and Ames, K. A. 2009. Evaluation of foliar fungicides on corn in Auburn, Illinois, 2008. Plant Disease Management Reports 3:FC001. Online publication. doi: 10.1094/PDMR02.

5. Bradley, C. A., and Ames, K. A. 2010. Effect of foliar fungicides on corn with simulated hail damage. Plant Dis. 94:83-86.

6. Brent, K. J., and Hollomon, D. W. 2007. Fungicide resistance in crop pathogens: how can it be managed? FRAC Monogr. No. 2, 2nd ed. Croplife International, Brussels.

7. Brent, K. J., and Hollomon, D. W. 2007. Fungicide resistance: the assessment of risk. FRAC Monogr. No. 2, 2nd ed. Croplife International, Brussels.

8. Carson, M. L. 1999. Gray leaf spot. Pages 22-23 in: Compendium of Corn Diseases, 3rd ed. D. G. White, ed. American Phytopathological Society, St Paul, MN.

9. Chin, K. M., Chavaillaz, D., Kaesbohrer, M., Staub, T., and Felsenstein, F. G. 2001. Characterizing resistance risk of Erysiphe graminis f. sp. tritici to strobilurins. Crop Prot. 20:87-96.

10. Chin, K. M., Wirz, M., and Laird, D. 2001. Sensitivity of Mycosphaerella fijiensis from banana to trifloxystrobin. Plant Dis. 85:1264-1270.

11. Fungicide Resistance Action Committee. 2010. List of plant pathogenic organisms resistant to disease control agents. Online publication. http//www.frac.info/frac/index.htm.

12. Glaab, J., and Kaiser, W. M. 1999. Increased nitrate reductase activity in leaf tissue after application of the fungicide kresoxim-methyl. Planta 207:442-448.

13. Groenewald, M. Groenewald, J. Z., Harrington, T. C., Abeln, E. C. A., Crous, P. W. 2006. Mating type gene analysis in apparently asexual Cercospora species is suggestive of cryptic sex. Fungal Genet. Biol. 43:813-825.

14. Grossman, K., Kwistkowski, J., and Caspar, G. 1999. Regulation of phytohormone levels, leaf senescence and transpiration by the strobilurin kresoxim-methyl in wheat (Triticum aestivum). J. Plant Physiol. 154:805808 .

15. Grossmann, K., and Retzlaff, G. 1997. Bioregulatory effects of the fungicidal strobilurin kresoxim-methyl in wheat (Triticum aestivum). Pestic. Sci. 50:11-20

16. Hewitt, H. G. 1998. Fungicides in Crop Protection. CAB International, New York.

17. Jutsum, A. R., Heaney, S. P., Perrin, B. M., and Wege, P. J. 1998. Pesticide 
resistance: assessment of risk and the development and implementation of effective management strategies. Pestic. Sci. 54:435-446.

18. Kubicek, C. P., Zehentgruber, O., El-Kalak, H., and Rohr, M. 1980. Regulation of citric acid production by oxygen: effect of dissolved oxygen tension on adenylate levels and respiration in Aspergillus niger. Eur. J. Appl. Microbiol. Biotechnol. 9:101-115.

19. Malandrakis, A. A., Markoglou, A. M., Nikou, D. M., Vontas, J. G., and Ziogas, B. N. 2006. Biological and molecular characterization of laboratory mutants of Cercospora beticola resistant to Qo inhibitors. Eur. J. Plant Pathol. 116:155-166.

20. Minagawa, N., and Yoshimoto, A. 1987. The induction of cyanide-resistant respiration in Hansenula anomala. J. Biochem. 101:1141-1146.

21. Mizutani, A., Miki, N., Yukioka, H., Tamura, H., and Masuko, M. 1996. A possible mechanism of control of rice blast disease by a novel alkoxyiminoacetamide fungicide, SSF126. Phytopathology 86:295-300.

22. Munkvold, G. P., Doerge, T., and Bradley, C. 2008. IPM is still alive for corn leaf diseases: look before you spray. In: Proc. 62nd Annu. Corn Sorghum Res. Conf. Chicago. CD-ROM, American Seed Trade Association, Alexandria, VA.

23. Munkvold, G. P., Martinson, C. A., Shriver, J. M., and Dixon, P. M. 2001. Probabilities for profitable fungicide use against gray leaf spot in hybrid maize. Phytopathology 91:477-484.

24. Myresiotis, C. K., Bardas, G. A., and Karaoglanidis, G. S. 2008. Baseline sensitivity of Botrytis cinerea to pyraclostrobin and boscalid and control of anilinopyrimidine- and benzimidazole-resistant strains by these fungicides. Plant Dis. 92:1427-1431.

25. Olaya, G., and Koller, W. 1999. Diversity of kresoxim-methyl sensitivities in baseline populations of Venturia inaequalis. Pestic. Sci. 55:1083-1088.

26. Olaya, G., Zheng, D., and Koller, W. 1998. Differential responses of germinating Venturia inaequalis conidia to kresoxim-methyl. Pestic. Sci. 54:230236.

27. Pasche, J. S., Wharam, C. M., and Gudmestad, N. C. 2004. Shift in sensitivity of Alternaria solani in response to QoI fungicides. Plant Dis. 88:181187.
28. Ruske, R. E., Gooding, M. J., and Jones, S. A. 2003. The effects of triazole and strobilurin fungicide programmes on nitrogen uptake, partitioning, remobilization and grain $\mathrm{N}$ accumulation in winter wheat cultivars. J. Agric Sci. 140:395-407.

29. Russell, P. E. 2004. Sensitivity baselines in fungicide resistance research and management. FRAC Monogr. No. 3. Crop Life International, Brussels.

30. Secor, G., Rivera, V., and Khan, M. 2009. Sensitivity of Cercospora beticola to foliar fungicides in 2008. Sugarbeet Res. Ext. Rep. 39:208-215.

31. Vincelli, P., and Dixon, E. 2002. Resistance to QoI (strobilurin-like) fungicides in isolates of Pyricularia grisea from perennial ryegrass. Plant Dis. $86: 235-240$.

32. Ward, J. M. J., Stromberg, E. L., Nowell, D. C., and Nutter, F. W., Jr. 1999. Gray leaf spot: a disease of global importance in maize production. Plant Dis. 83:884-895.

33. Wise, K. A., Bradley, C. A., Pasche, J. S., Gudmestad, N. C., Dugan, F. M. and Chen, W. 2008. Baseline sensitivity of Ascochyta rabiei to azoxystrobin, pyraclostrobin, and boscalid. Plant Dis. 92:295-300.

34. Wong, F. P., and Wilcox, W. F. 2000. Distribution of baseline sensitivities to azoxystrobin among isolates of Plasmopara viticola. Plant Dis. 84:275-281.

35. Wong, F. P., and Wilcox, W. F. 2002. Sensitivity to azoxystrobin amon isolates of Uncinula necator: baseline distribution and relationship to myclobutanil sensitivity. Plant Dis. 86:394-404

36. Wu, Y. X., and von Tiedemann, A. 2001. Physiological effects of azoxystrobin and epoxiconazole on senescence and oxidative status of wheat Pestic. Biochem. Physiol. 71:1-10.

37. Wu, Y. X., and von Tiedemann, A. 2002. Impact of fungicides on active oxygen species and antioxidant enzymes in spring barley (Hordeum vulgare L.) exposed to ozone. Environ. Pollut. 116:37-47.

38. Ypema, H. L., and Gold, R. E. 1999. Kresoxim-methyl: modification of a naturally occurring compound to produce a new fungicide. Plant Dis. 83:419

39. Ziogas, B. N., Baldwin, B. C., and Young, J. E. 1997. Alternative respiration: a biochemical mechanism of resistance to azoxystrobin (ICIA 5504) in Septoria tritici. Pestic. Sci. 50:28-34. 